\title{
NUMERICAL ANALYSIS OF IN-PLANE BEHAVIOUR OF MASONRY INFILLED RC FRAMES USING MACRO AND MICRO MODELS
}

\author{
Kamaran Mohammed Kareem ${ }^{1}$, Hunar Farid Hama Ali, Hiwa Hamed Sharif, \\ BEDAR RAUOF HASSAN and FARAYDON HAMA RASH W. MAHMOD \\ Dept. of Civil Engineering, University of Halabja, Kurdistan Region-Iraq
}

(Accepted for Publication: December 8, 2020)

\begin{abstract}
A number of simplified methodologies have been proposed aiming at preparing numerical tools suitable for engineering application, to predict the nonlinear seismic behavior of infilled frame structures. In this paper, a 2D discrete macro element model (DMEM) for the simulation of the in-plane behavior of RC frames with infill walls, is presented, validated with an experimental result that investigate the influence of infill masonry, and evaluated with a proposed Finite Element model (FEM). In this model, the frame members are modeled by beam-column elements with lumped plasticity, while the infills contribution are modeled by plane discrete-element. As an extended study, a 2D prototype of multistory frame building, for which the results of pseudo dynamic tests are available, is investigated. The ability of the considered DMEM to predict the in-plane behavior of infill masonry elements is investigated, the merits and drawbacks are highlighted.
\end{abstract}

KEYWORDS: Infill frame wall, Modeling masonry, DMEM, FEM, In-plane load

\section{INTRODUCTION}

I nfill frame buildings are adopted widely as the common building system throughout the world. Infill masonry have been built in many buildings for non-structural purposes, and generally in the design and analysis process ignored their structural contribution. Numerous authors reported that neglecting infill wall structural contribution in the structural analysis is not always safe, since, infill wall increases lateral strength and stiffness of the buildings (Kunnath et al. 1990; Mehrabi et al. 1996; Negro and Colombo 1997; Buonopane and White 1999; Dolsek and Fajfar 2001; Asteris 2003; Kakaletsis and Karayannis 2008). However, the everchanging contact conditions of the infill wall with bounding frame and high nonlinearity material response of the infill masonry lead to modeling the infilled frame nonlinear response to become a challenging computational problem.

An extensive nonlinear finite element method is required for modelling the infilled frame nonlinear behaviour (Madan et al. 1997; Mehrabi and Shing 1997; Harpal et al. 1998; Ghosh and Amde 2002; Stavridis and Shing 2010; Asteris 2008), which is capable of simulating the infill-frame interaction and the masonry degrading behaviour through accurate nonlinear interface elements (Macorini and Izzuddin 2011; D’Ayala et al. 2009). However, computational resources are required for detailed approaches that are hard to use in actual cases and are difficult to achieve for large buildings. Simplified methodologies were developed by many authors to provide suitable numerical tools

kamaran.kareem@uoh.edu.iq, hunar.hamaali@uoh.edu.iq, hiwahamidenineering@gmail.com, bedar.hassan@uoh.edu.iq, faraydon.hmahmod@yahoo.com 
for engineering practice, based on macro modeling approach for simulating the infill frame building response under seismic loads, which in this method the infill wall is simulated through an equivalent simplified schemes that are able to account for the infill's influence on the structural behaviour (Rodrigues et al. 2010; Asteris et al. 2015; Ellul and D' Ayala 2012). The 'diagonal strut model' practical approach have been commonly used. The infill wall is considered by an equivalent strut under diagonal compression and the first proposal is presented by (Polyakov. 1960, Holmes. 1961). Many alternatives through this approach have been proposed for considering the presence of opening and the evaluation of the strut width, and some others replaced the infills by a set of struts (Liauw and Kwan 1984, El-Dakhakhni et al. 2003, Thiruvengadam 1985). Some authors (Asteris et al. 2011, Kareem and Güneyisi. 2018) reported a comprehensive review regarding the existing equivalent diagonal strut modelling approaches for infilled masonry buildings.

Marques and Lourenco 2011; Calio' et al. 2012; Marques and Lourenco 2014; Calio` and Panto` 2014, recently proposed an alternative new modeling approach for the simulation of unreinforced masonry and mixed reinforced concrete masonry structures under seismic action. In this modeling approach, the infill wall is simulated by a simple $2 \mathrm{D}$ geometrical equivalent mechanical macro models that is efficient for governing the in plane non-linear behaviour of masonry wall while the bounding frame members is simulated by lumped plasticity beam-column elements, and the opening can be considered through a mesh of macro element models.

In this study, the DMEM is validated with experimental results, by adopting a commercial software SAP 2000 V18 (2016) and nonlinear finite element software ABAQUS (2011).
Mainly a specific software 3DMacro (2015) has been using for modeling DMEM, until recently Kareem and Pantò (2019) used the software SAP 2000 , because this program is more accurate and used widely for research purpose and practical engineering. In addition, the 1D non-linear link in SAP2000 can be employed with hysteretic behaviour and advanced constitutive laws.

Finally, the nonlinear response of an infilled frame multi-story building prototype has been investigated by employing DMEM approach through nonlinear static analysis. The building prototype has been built under pseudo dynamic test with a real scale at the ELSA laboratory in ISPRA (Carvalho and Coelho 2001), where (Dolšek and Fajfar 2008) already have performed some numerical simulations by considering single strut modeling approach. The building prototype is designed for vertical load only and represented a typical residential building. The study's objectives are summarized as follows:

- To validate the presented DMEM, validated with an experimental result and proposed FEM.

- Further investigation was carried out on the role of DMEM, through a comparison with multi-story prototype experimental results

\section{THE PRESENTED DMEM}

In the presented model, the infill frame is simulated through a hybrid approach. In this approach the non-linear beam-column elements is employed for the surrounding frame with concentrated plasticity while the infill masonry is modelled by a plane discrete element (Calio' and Panto2014; Calio` et al. 2012). The discrete element is simply represented through a mechanical scheme in which the masonry shear behaviour is governed by an articulated quadrilateral with rigid edges connected by two diagonal non-linear links and four hinges.

kamaran.kareem@uoh.edu.iq, hunar.hamaali@uoh.edu.iq, hiwahamidenineering@gmail.com, bedar.hassan@uoh.edu.iq, faraydon.hmahmod@yahoo.com

${ }^{1}$ Corresponding author: Department of Civil Engineering, University of Halabja, Kurdistan Region, Iraq 
Further the sliding and flexural response controlled by a discrete distribution of non-linear orthogonal and longitudinal springs respectively which interact or supports each side of quadrilateral with other elements, each interface is discretised by $\boldsymbol{n}$ nonlinear links perpendicular to the panel side plus a longitudinal spring
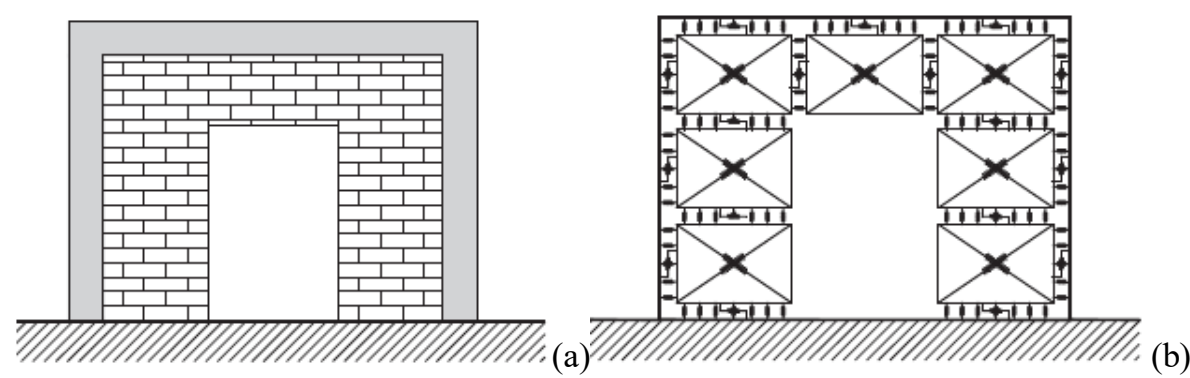

Fig. (1): infilled frame modelling: (a) geometrical layout with opening (b) DMEM simulation.

According to Pantò et al. (2017), for interface links an elasto-plastic constitutive law, with limited ductility, is considered in tensile/compression while an elastic linearsoftening constitutive law characterizes the diagonal links of the panel. Finally, the sliding mechanisms in the simulations are neglected, therefore, the longitudinal interface links are substituted by an internal constrain. The nonlinear force-displacement relationship for the interface and diagonal 1D-links has been calibrated according to the procedures reported by (Kareem and Pantò 2018). parallel to the panel sides. In spite of its simplicity, this mechanical scheme is capable of simulating the in-plane shear (sliding and diagonal shear) failure modes for a portion of masonry wall under in-plane loads (Calio` et al. 2012) (see Fig.

$1)$.

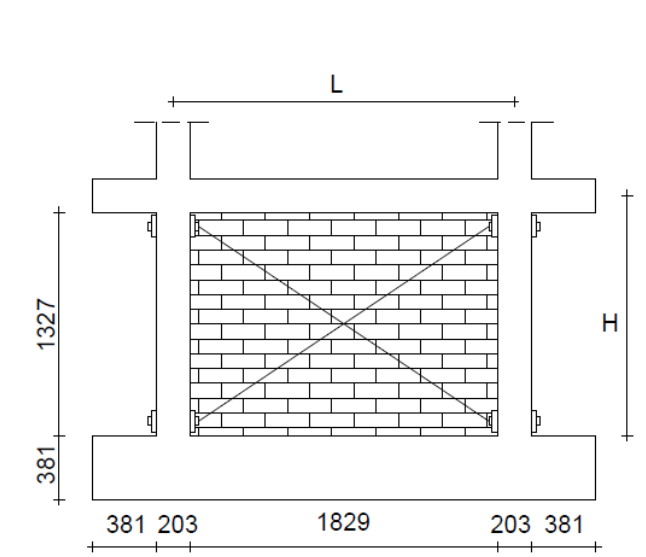

\section{NUMERICAL APPLICATIONS}

The results of an experimental test as reported in (Al-Chaar et al. 2002) was implemented to simulate the masonry infilled frame with nonlinear behavior. This experiment conducted by the Construction Engineering Research Laboratory, as the existing building dormitories, constructed in the USA during 1950s, was assessed under seismic action. The structural response of nonductile fully infilled masonry RC frames has been investigated in the experiment.

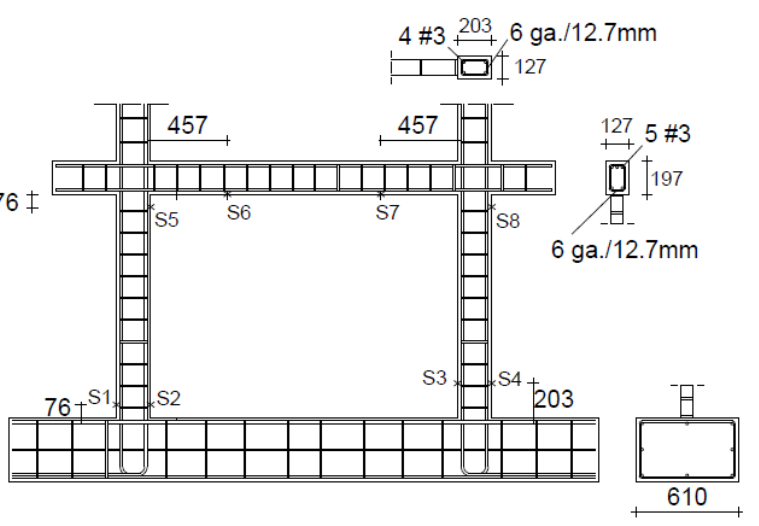

Fig. (2): Experiment layout (a) the geometrical properties and (b) reinforcement detail (Caddemi et al 2013).

kamaran.kareem@uoh.edu.iq, hunar.hamaali@uoh.edu.iq, hiwahamidenineering@gmail.com, bedar.hassan@uoh.edu.iq, faraydon.hmahmod@yahoo.com

${ }^{1}$ Corresponding author: Department of Civil Engineering, University of Halabja, Kurdistan Region, Iraq 
In this experimental work, five frames with half-scale were tested under monotonic in-plane lateral loading. All models are single-story RC frames with different bay (single, double, or triple) construction. The single infilled frame results are reported and validated in this study.

Table (1): Concrete and reinforcement mechanical properties.

\begin{tabular}{ccccccc}
\hline \multicolumn{3}{c}{ Concrete } & \multicolumn{2}{c}{ Reinforcement } \\
\hline$E(G P a)$ & $\sigma_{c}(M P a)$ & $\varepsilon_{c o}(\%)$ & $\varepsilon_{c u}(\%)$ & $w\left(k N / m^{3}\right)$ & $E(G P a)$ & $f_{y}(M P a)$ \\
\hline 29.99 & 38.5 & 0.2 & 0.35 & 25 & 200 & 377 \\
\hline
\end{tabular}

Table (2): Infilled masonry mechanical properties.

\begin{tabular}{|c|c|c|c|c|c|c|c|c|c|c|}
\hline \multicolumn{5}{|c|}{ Flexural behavior } & \multirow{2}{*}{\multicolumn{2}{|c|}{ Diagonal shear behavior }} & \multicolumn{4}{|c|}{ Sliding shear behavior } \\
\hline & & & & & & & \multicolumn{2}{|c|}{ Horizontal } & \multicolumn{2}{|c|}{ vertical } \\
\hline $\begin{array}{c}w \\
\left(k N / m^{3}\right)\end{array}$ & $\begin{array}{c}E_{m} \\
(M P a)\end{array}$ & $\begin{array}{c}f_{m} \\
(M P a)\end{array}$ & $\begin{array}{c}f_{t m} \\
(M P a)\end{array}$ & $\begin{array}{c}\lambda \\
(\mathrm{cm})\end{array}$ & $\begin{array}{c}G_{m} \\
(M P a)\end{array}$ & $\begin{array}{c}c \\
(M P a)\end{array}$ & $\mu$ & $\begin{array}{c}c \\
(M P a) \\
\end{array}$ & $\begin{array}{c}G_{m} \\
(M P a)\end{array}$ & $\mu$ \\
\hline 18 & 2500 & 5 & 0.15 & 10 & 1000 & 0.3 & 0.3 & 0.15 & 0.7 & 0.4 \\
\hline
\end{tabular}

The material characteristics and configuration details of the considered models are reported by (Al-Chaar et al. 2002). For more explanation, Fig. 2 presents the layout corresponding to the reinforcement details and geometrical characteristics. The elastic perfectly plastic type of the stress-strain behaviour has been assumed for reinforcing bars, and for concrete in compression it is assumed that the stress/strain relationship to be of parabolic type up the strain $\varepsilon_{\mathrm{co}}$ and of rectangular type up to the ultimate strain $\varepsilon_{\mathrm{cu}}$. The nonlinear spring characteristics that govern the response of the macro-element discretization of infill masonry have been assessed with regard to the calibration method previously reported and summarised with more details by (Calio` et al. 2012), which has been simulated in a (3DMAcro 2015) structural software and by (Kareem and Pantò 2018) with the solver 'SAP2000'. In this investigation the analyses are conducted within the FE software 'SAP2000' with non-linear static analysis. The DMEM is analyzed by using non-linear onedimensional links, rigid elements hinged at the vertexes of the panel are used to simulate the edges of the quadrilateral. The required input parameters for calibrating the discrete element and the bounding frame are presented in table 1 and 2 .

The presented DMEM are also compared with the finite element (FE) model. In the FEM used in this paper, the simplified micro model is considered for simulating infill wall. In this approach the units are expanded by adding a half thickness of mortar on each side in horizontal and vertical directions, where the expanded units are simulated as a continuum element, and the expanded units are adjoining with each other as a series of dis-continuum elements. The FE software ABAQUS [2011] has been implemented for evaluating the seismic response of the considered experimental models. The frame members and expanded masonry units are modelled by (C3D8R) an 8-node 3-D stress linear brick element. The reinforcement is modelled with truss element T3D2, which is embedded in the concrete element. The concrete damage plasticity (CDP) model was selected for modelling the expanded units and bounding frame members, the CDP model is based on the proposed primary models of (Lubliner et al. 1989) and (Lee and Fenves. 1998). The

kamaran.kareem@uoh.edu.iq, hunar.hamaali@uoh.edu.iq, hiwahamidenineering@gmail.com, bedar.hassan@uoh.edu.iq, faraydon.hmahmod@yahoo.com

${ }^{1}$ Corresponding author: Department of Civil Engineering, University of Halabja, Kurdistan Region, Iraq 
reinforcement was modelled based on a bilinear yield criterion.

Surface to surface contact are used to simulate the interaction of the adjacent expanded units as well as between infill wall and the RC frame members. The surface based cohesive behaviour are used to simulate the interactions with the hard contact and penalty tangential model. Fig. 3 represent the FEM schematic representation of the experimental model. The models bottom side are fixed, the analysis is performed using ABAQUS/standard dynamic implicit under monotonic lateral displacement load applied at the end of the beam. All the mechanical parameters characterizing the interfaces are reported in 3.

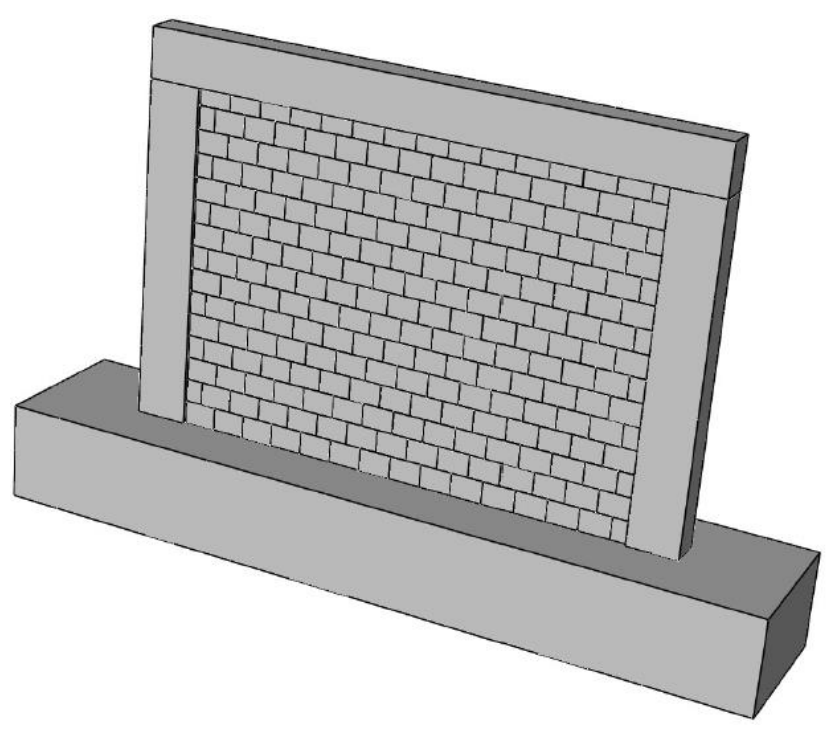

Fig. (3): Finite element model

Table (3): Mechanical properties of interaction

\begin{tabular}{cccccccc}
\hline \multicolumn{1}{c}{ Horizontal Interaction } \\
\hline$\mu$ & $k_{n}$ & $\begin{array}{c}k_{t} \\
(N / m)\end{array}$ & $\begin{array}{c}k_{t} \\
(N / m)\end{array}$ & $\begin{array}{c}t_{n}^{\max } \\
\left(N / m^{2}\right)\end{array}$ & $\begin{array}{c}\tau^{\max } \\
\left(\mathrm{N} / \mathrm{m}^{2}\right)\end{array}$ & $\begin{array}{c}\text { G-Mode I } \\
(\mathrm{Nm})\end{array}$ & $\begin{array}{c}\text { G-Mode II } \\
(\mathrm{Nm})\end{array}$ \\
\hline 0.7 & 33 & 14 & 14 & 0.059 & 0.172 & 0.022 & 0.22 \\
\hline$\mu$ & $k_{n}$ & $k_{t}$ & $k_{t}$ & $t_{n}^{\max }$ & $\tau^{\max }$ & G-Mode I & G-Mode II \\
& $(N / m)$ & $(N / m)$ & $(N / m)$ & $\left(N / m^{2}\right)$ & $\left(N / m^{2}\right)$ & $(N m)$ & $(\mathrm{Nm})$ \\
\hline 0.7 & 29 & 12.5 & 12.5 & 0.059 & 0.172 & 0.018 & 0.18 \\
\hline
\end{tabular}

kamaran.kareem@uoh.edu.iq, hunar.hamaali@uoh.edu.iq, hiwahamidenineering@gmail.com, bedar.hassan@uoh.edu.iq, faraydon.hmahmod@yahoo.com 

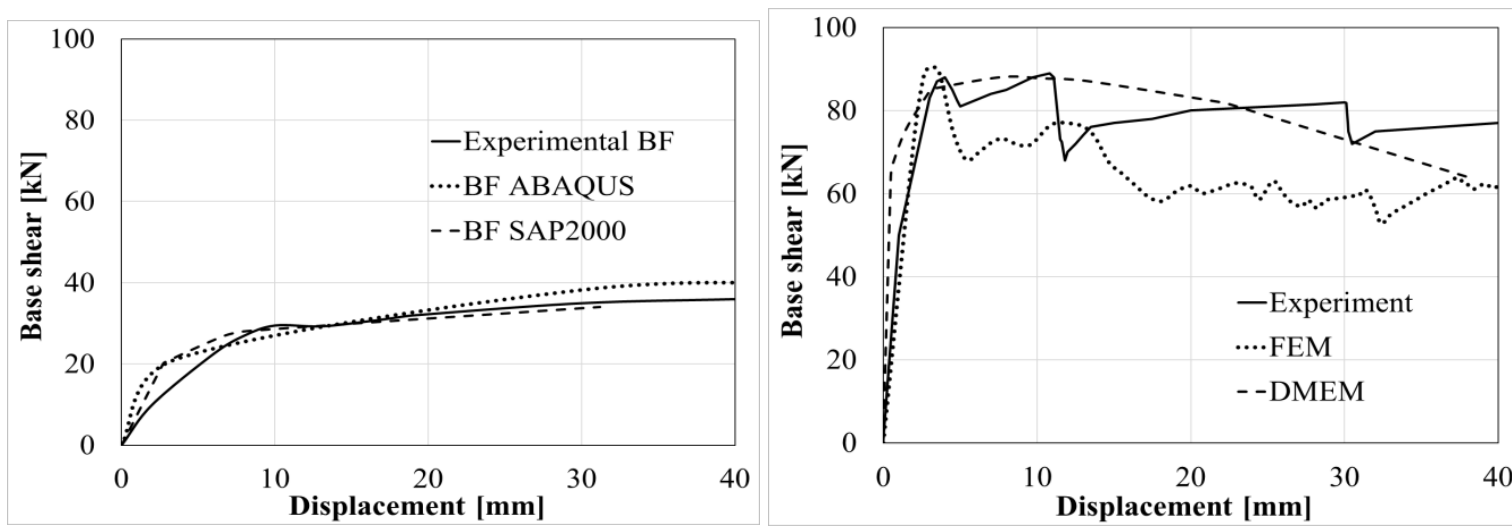

(a)

(b)

Fig. (4): Numerical and experimental capacity curve (a) bare frame (b) full infill frame.

The first numerical validation is applied to simulate the basic single-bay frame behaviour without taking into account masonry infilled. The results obtained for this validation is reported in Fig. 4a which shows the experimental and two numerical results (SAP2000 and ABAQUS) regarding the bare RC frame (BF). The results demonstrated a strong agreement between numerical applications and experimental results in term of capacity curve. The outcome results with regard to the single bay infilled frame are presents in Fig. $4 \mathrm{~b}$. The figure shows the pushover curve (base shear versus the top horizontal displacement), the continuous line represents the experimental results while the dashed and dotted lines refers to the numerical DMEM and FEM simulation respectively. The DMEM has been implemented by taking a $3 \times 3$ discretization macro-element.
By observing the maximum reached forces and displacements, the agreement between numerical and experimental results can be considered satisfactory both in terms of initial stiffness and peak lateral resistance, however, the DMEM provided an over estimation of the elastic stiffness. In the softening stage the presented numerical models show different behaviors, the DMEM strength degradation is more coherent to the experimental model than FEM.

In Fig. 5 the corresponding damage crack patterns obtained experimentally is compared with the damage behavior and stress path predicted by the numerical analysis, with regard to the ultimate drift value of $2.86 \%$. The presented DMEM is capable to capture the distribution of damage on both the infill wall and the bounding frame as compared to experimental and

FEM.

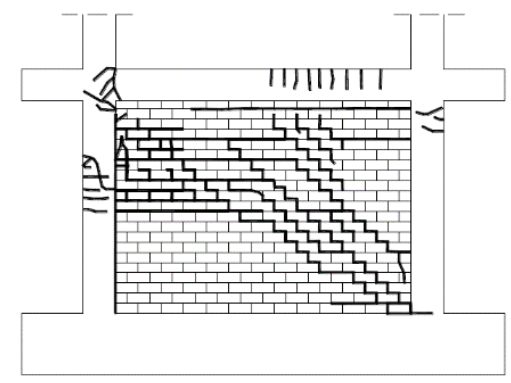

(a)

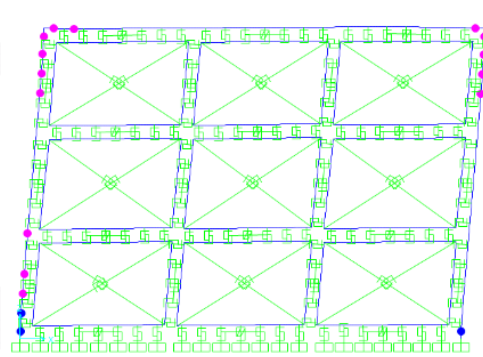

(b)

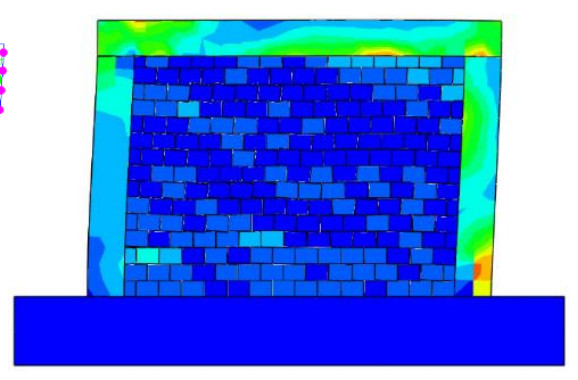

(c)

Fig. (5): Experimental damage scenario, from (a) reference [Caddemi et al 2013], (b) DMEM, and (c) FEM.

kamaran.kareem@uoh.edu.iq, hunar.hamaali@uoh.edu.iq, hiwahamidenineering@gmail.com, bedar.hassan@uoh.edu.iq, faraydon.hmahmod@yahoo.com

${ }^{1}$ Corresponding author: Department of Civil Engineering, University of Halabja, Kurdistan Region, Iraq 
Based on the force displacement curve the degradation of the lateral stiffness is calculated and is shown in Fig. 6 with respect to the lateral drift. It is observed that by increasing lateral drifts the stiffness decreases with an exponential trend, and this trend indicate that at early stage of loading the experimental and FEM presents lower initial stiffness than DMEM, and both DMEM and experimental model show similar response in term of stiffness degradation, as the FEM is diverged from experimental path especially in the moderate drift level, this behavior exhibit the accuracy of the modeling approach in the

DMEM

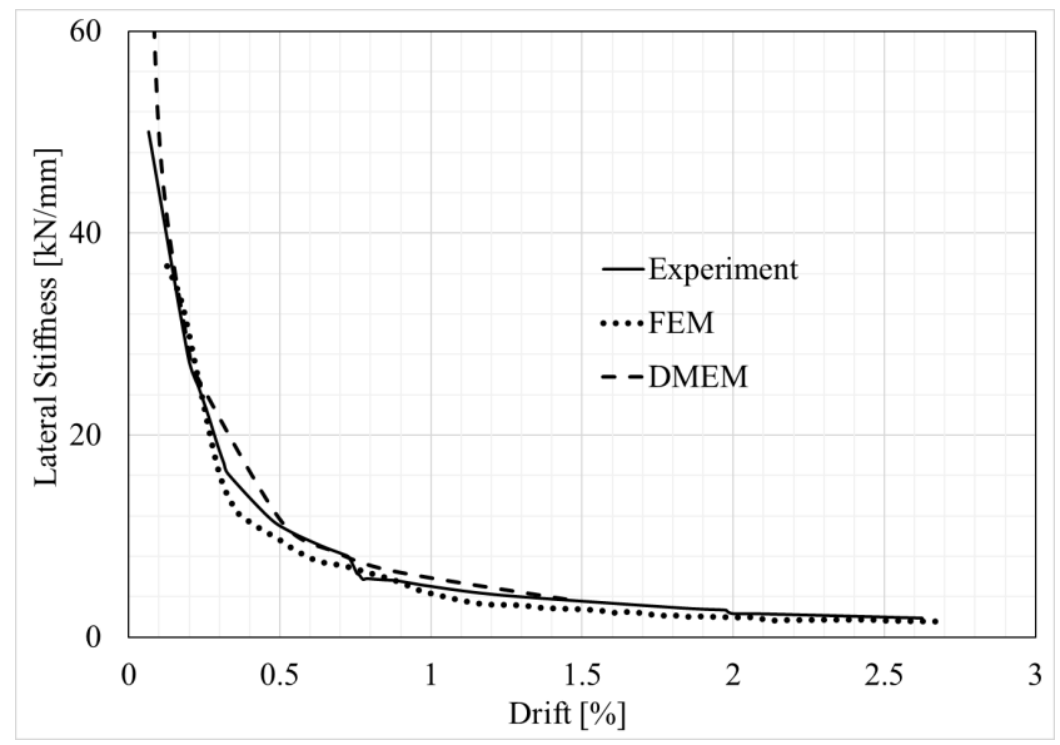

Fig. (6): Reduction of lateral stiffness versus different levels of lateral drift

Fig. 7 shows the total dissipated energy during the monotonic loading versus lateral drifts. By comparing the dissipated energy at a high drift level in the numerical models with the experimental model, it is observed that the FEM dissipated less energy than the experimental model, and it also observed that the DMEM dissipated almost the same energy as the experimental model.

kamaran.kareem@uoh.edu.iq, hunar.hamaali@uoh.edu.iq, hiwahamidenineering@gmail.com, bedar.hassan@uoh.edu.iq, faraydon.hmahmod@yahoo.com 


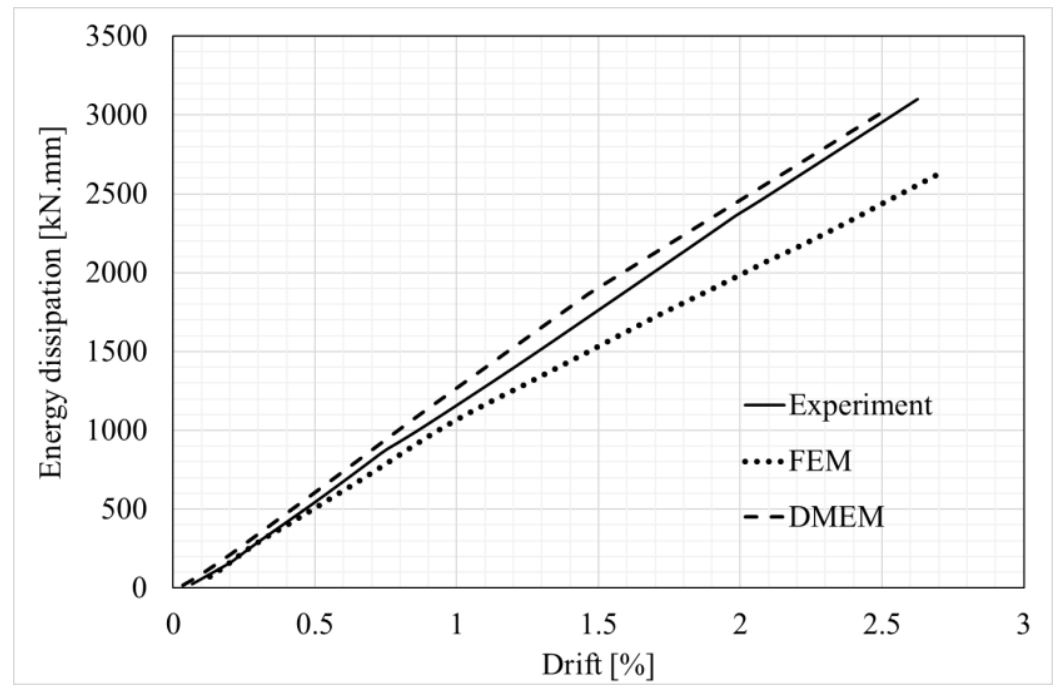

Fig. (7): Dissipation of Energy versus lateral drifts

Depending on the above discussions, it is possible to conclude that the DMEM despite the simplicity of the constitutive laws, capable of predicting experimental behaviour with a sufficient approximation.

\section{NUMERICAL MODEL OF A MULTI- STORY 2D FRAME}

This section illustrates the implementation of the presented DMEM in order to investigate the nonlinear behavior of a prototype building with real scale subjected to pseudo dynamic tests in the ELSA laboratory (Carvalho and Coelho 2001). The frame consists of 4-storey with 3-bay infilled RC frame, assumed to represent a typical RC building constructed during $(1960-1980)$ in the Mediterranean area and Southern Europe without considering seismic provisions. The frame geometrical layout is presented in Fig. 8, where the two considered configurations with and without infill walls are reported. The selfweight and super imposed dead loads applied at each story level are representative of RC slabs $0.15 \mathrm{~m}$ thick and $4.00 \mathrm{~m}$ wide. The dead load calculated at the first, second and third story equal to $36.4 \mathrm{kN} / \mathrm{m}$ and at the fourth story equal to $32 \mathrm{kN} / \mathrm{m}$. Mechanical properties reported in Table 4 and Table 5 was used as input parameters in the numerical DMEM. In this study nonlinear numerical models (bare and infill) of the prototypes were analyzed and compared to the experimental model results.

kamaran.kareem@uoh.edu.iq, hunar.hamaali@uoh.edu.iq, hiwahamidenineering@gmail.com, bedar.hassan@uoh.edu.iq, faraydon.hmahmod@yahoo.com 

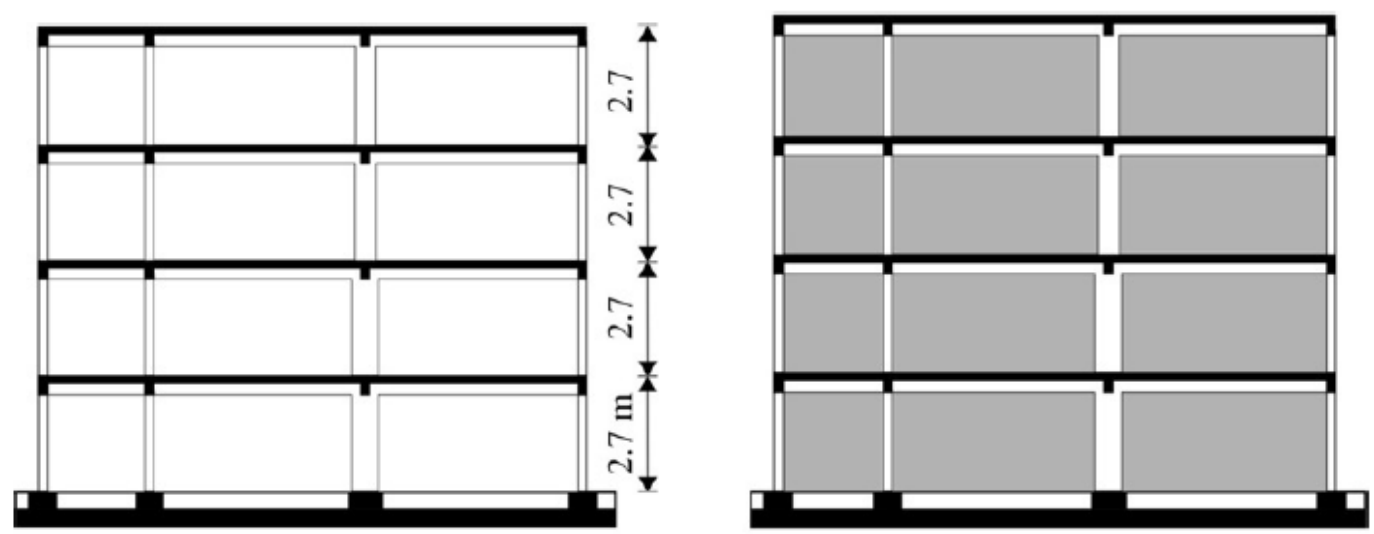

Bare frame

Full infill frame
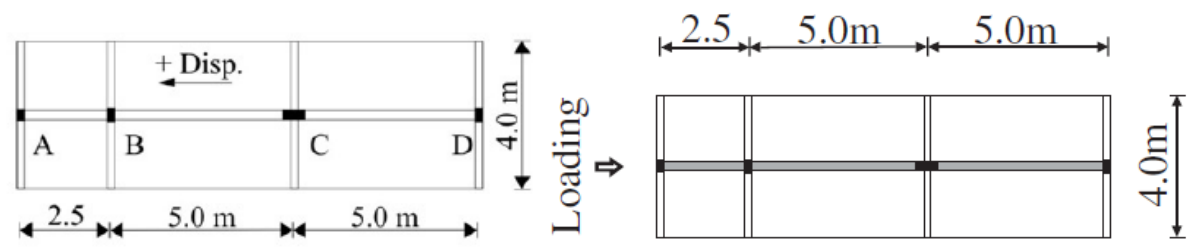

Fig. (8): Structural schemes geometry from reference (Dolšek and Fajfar 2008d)

The following assumptions have been made in the numerical modeling program:

The concrete compressive stress/strain relationship is a parabolic type, until the peak stress and strain, then a rectangular type, up to the ultimate strain, the concrete tension stress/strain relationship is linear until $\mathrm{f}_{\mathrm{ct}}$. The steel stress/strain relationship is an elasticperfectly plastic. For determining the mechanical characteristics of infill walls, laboratory compression test of hollow ceramic blocks with each side $1.5 \mathrm{~cm}$ thick render has been conducted (Pinto et al. 2001; Varum 2003). For the interfaces orthogonal links ruling the axial- flexural behaviour, an elasto plastic relationship, with limited stress in compression and tension as well as limited ductility governed by a fracture energy in compression and tension $\left(\mathrm{G}_{\mathrm{c}}, \mathrm{G}_{\mathrm{t}}\right)$ has been considered, while for the diagonal and sliding nonlinear links, governing shear-diagonal strength by $\left(f_{v o}, \tan (\varnothing)\right)$ and shear-sliding mechanisms by (c, $\mu$ ) an elasto-plastic relationship with elastic shear modulus $(\mathrm{G})$ and the Coulomb criterion has been assumed. For the diagonal shear mechanism governed by fixed fracture energy, a limited ductility is considered, while an unlimited ductility is considered for the sliding

Table (4):Concrete and reinforcement mechanical properties.

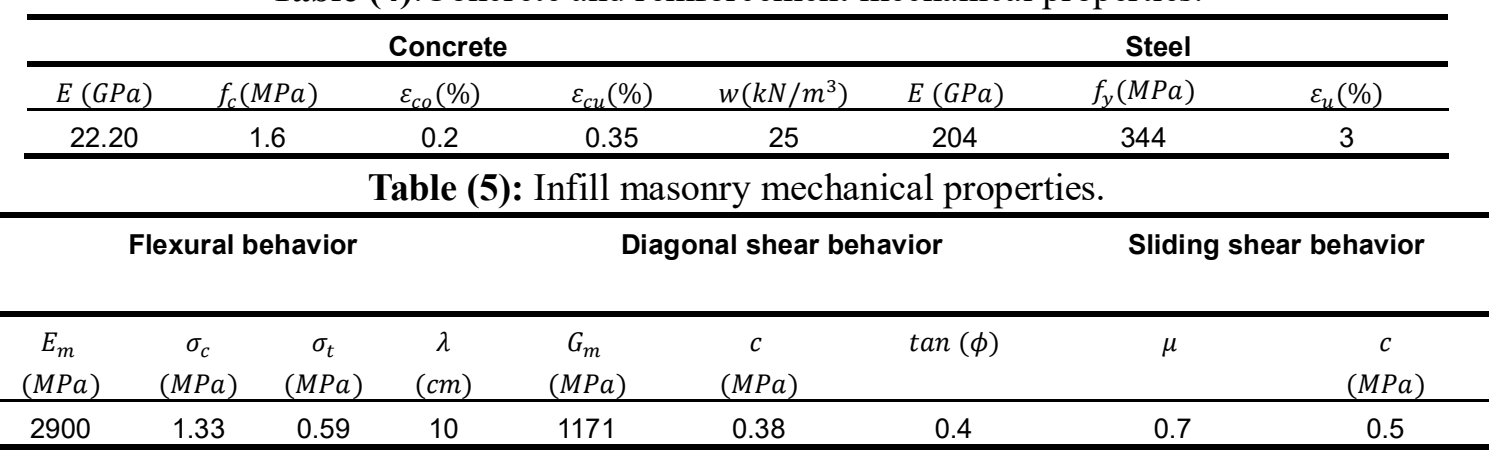

kamaran.kareem@uoh.edu.iq, hunar.hamaali@uoh.edu.iq, hiwahamidenineering@gmail.com, bedar.hassan@uoh.edu.iq, faraydon.hmahmod@yahoo.com

${ }^{1}$ Corresponding author: Department of Civil Engineering, University of Halabja, Kurdistan Region, Iraq 
Fig. 8 presents an experimental tests layout for both bare and the infilled frame (Carvalho and Coelho 2001). The software SAP2000 have been implemented for the analysis presented in this investigation, in which the DMEM has been applied.

A nonlinear static (pushover) analysis was performed to investigate the nonlinear behaviour under seismic loads. In order to compare the numerical model results with experimental results, the pushover curves, regarding the full infilled frame, have been contrasted with the envelope curve obtained experimentally by the pseudo-dynamic tests (Carvalho and Coelho 2001) as reported in Dolšek and Fajfar (2008d) by implementing an equivalent strut (EDS) model. As can be seen from Fig. 9, which reported a comparison in terms of base shear versus lateral drift at the first level, it is obvious that the DMEM provide good and acceptable results in terms of initial stiffness and the postpeak

behaviour.

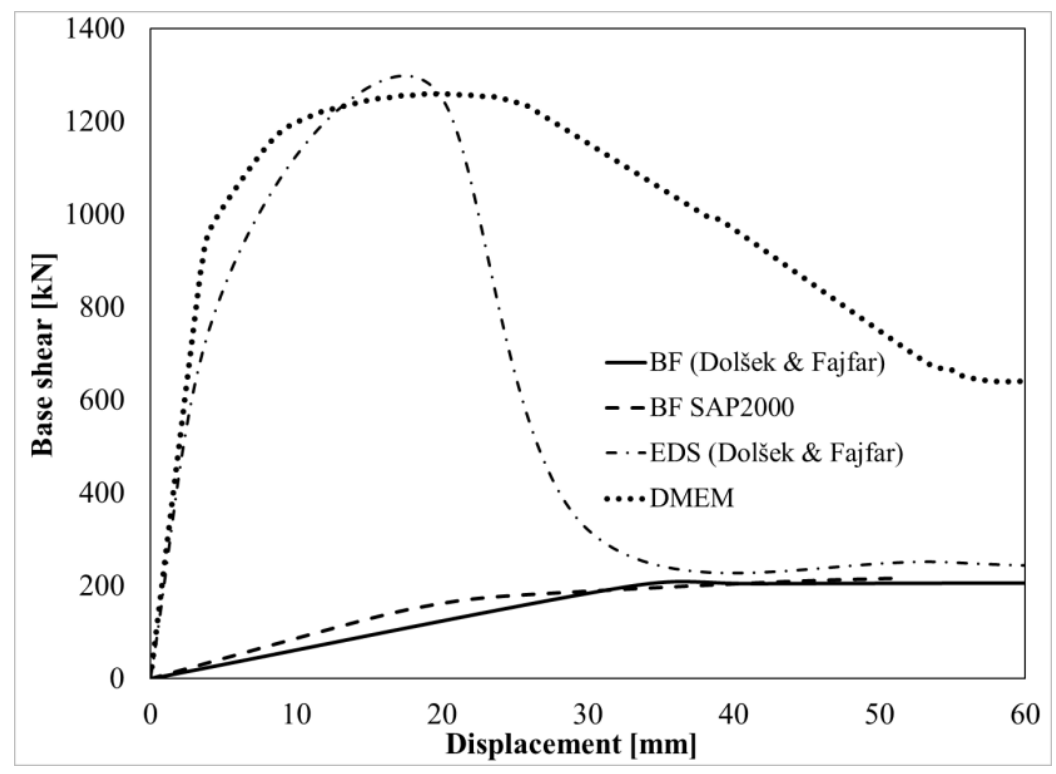

Fig. (9): Experimental and numerical pushover curves.

The damage patterns regarding the final step of the analysis, for both bare frame and infilled frame models are presented in Fig. 10a and b. The Figures, illustrates the high influence of the infill on the collapse mechanism of the frame. As can be seen, the susceptible levels for failure in the bare frame model are 2nd and 3rd levels, while in the DMEM the mechanism is concentrated at the first level. Moreover, the distributions of the frame plastic hinges were significantly changed due to the presence of the infill walls, especially a larger plastic demand was observed in the first level of the infilled frame when compared to the bare frame model. It is worth to mention that, the DMEM gave a reliable prediction of the damage pattern in the frame, also it was able to follow the progressive damage along the columns and beams.

kamaran.kareem@uoh.edu.iq, hunar.hamaali@uoh.edu.iq, hiwahamidenineering@gmail.com, bedar.hassan@uoh.edu.iq, faraydon.hmahmod@yahoo.com 


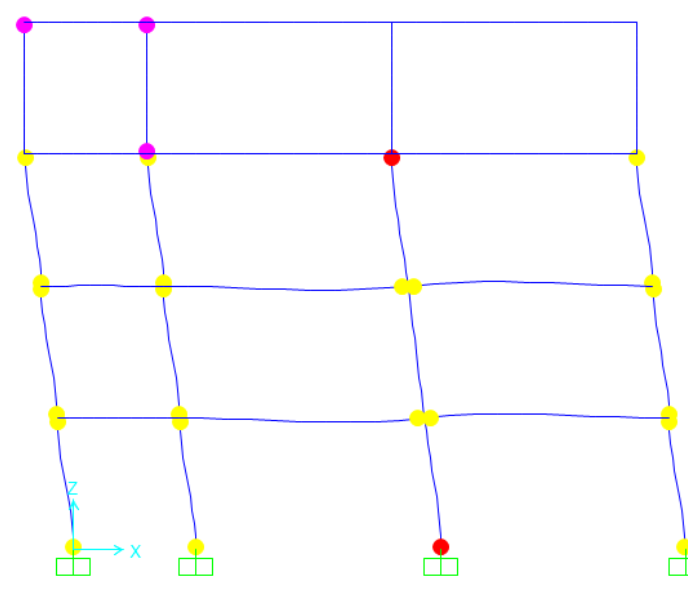

(a)

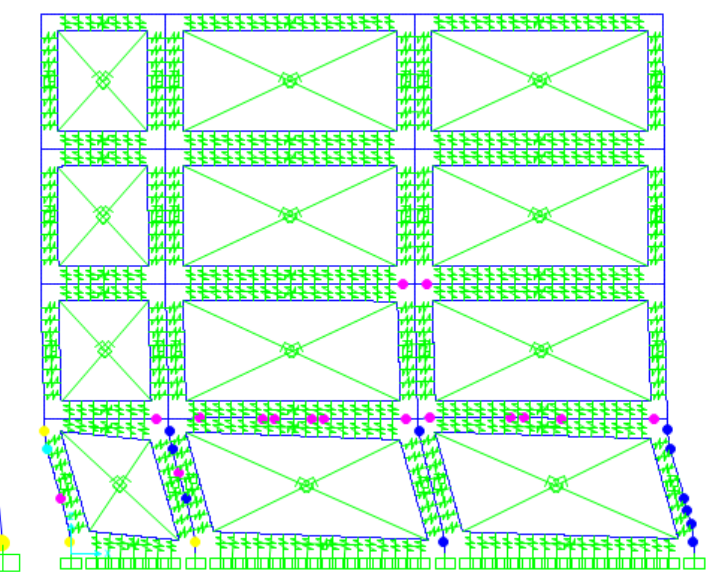

(b)

Fig. (10): Failure mechanisms of (a)bare frame, (b)DMEM

\section{CONCLUSIONS}

In the current design procedure, the seismic assessment of RC frames and structural design of buildings is conducted without considering the contribution of masonry infills. However, as reported by many researchers, neglecting the effect of infill wall and bounding frame interaction is not always safe, because the infill panels can remarkably affect the stiffness and the peak lateral strength of the frame. Moreover, due to the nonlinear behavior of infill masonry and the variable contact conditions along the frame and infill boundaries resulted in a challenging computational problem to simulate the nonlinear behaviour of infilled frame buildings.

In the current study, a relatively new DMEM is implemented, validated with experimental results by using previous experimental tests on several infilled frame structures, and numerically investigated by adopting FE software ABAQUS. The DMEM was implemented in the advanced structural software SAP 2000, which is widely used for engineering applications.

The results obtained in this study demonstrated that the explicit modelling of the infills by the innovative DMEM method could capture a more realistic behavior, which can be used for complex geometries, and illustrated a high influence of the infills, in terms of stiffness of the system and lateral strength. A satisfactory agreement between the numerical modeling with experimental results in terms of response and capacity curves were observed. Finally, the results also demonstrated that the infill wall can significantly affect the failure mechanisms of the frame, these influences are clearly noticed in the numerical model, as the geometrical consistency of the DMEM, allow the simulation of the nonlinear spread interaction between infill and frame.

\section{REFERENCE}

Mehrabi A, Shing PB, Schuller M, Noland J (1996) Experimental evaluation of masonry-infilled RC frames. J Struct Eng 122(3):228-237

Buonopane SG, White RN (1999) Pseudodynamic testing of masonry infilled reinforced concrete frame. J Struct Eng 125(6):578-589

Asteris P (2003) Lateral stiffness of brick masonry infilled plane frames. J Struct Eng 129(8):1071-1079

Kunnath S, Reinhorn A, Park Y (1990) Analytical modeling of inelastic seismic response of R/C structures. J Struct Eng 116(4):996-1017

Negro P, Colombo A (1997) Irregularities induced by

kamaran.kareem@uoh.edu.iq, hunar.hamaali@uoh.edu.iq, hiwahamidenineering@gmail.com, bedar.hassan@uoh.edu.iq, faraydon.hmahmod@yahoo.com 
non-structural masonry panels in framed buildings. Eng Struct 19:576-585

Kakaletsis DJ, Karayannis CG (2008) Influence of masonry strength and openings on infilled R/C frames under cycling loading. J Earthq Eng 12(2):197-221

Dolsek M, Fajfar P (2001) Soft storey effects in uniformly infilled reinforced concrete frames. J Earthq Eng 5:1-12

Mehrabi AB, Shing PB (1997) Finite element modeling of masonry-infilled RC frames. J Struct Eng 123(5):604-613

Madan A, Reinhorn AM, Mander JB, Valles RE (1997) Modeling of masonry infill panels for structural analysis. J Struct Eng 123(10):12951302

Ghosh AK, Amde AM (2002) Finite element analysis of infilled frames. J Struct Eng 128(7):881889

Harpal Singh, Paul DK, Sastry VV (1998) Inelastic dynamic response of reinforced concrete infilled frame. Comput Struct 69:685-693

Asteris PG (2008) Finite element micro-modeling of infilled frames. Electron J Struct Eng 8:1-11

Stavridis A, Shing PB (2010) Finite-element modeling of nonlinear behavior of masonryinfilled RC frames. J Struct Eng 136(3):285296

D'Ayala D, Worth J, Riddle O (2009) Realistic shear capacity assessment of infill frames: comparison of two numerical procedures. Eng Struct 31(8):1745-1761

Macorini L, Izzuddin BA (2011) A non-linear interface element for 3D mesoscale analysis of brick-masonry structures. Int $\mathrm{J}$ Numer Methods Eng 85:1584-1608. ISSN 0029-5981

Ellul F, D'Ayala D (2012) Realistic FE models to enable push-over non linear analysis of masonry infilled frames. Open Constr Build Technol J 6(1):213-235

Asteris P, Cavaleri L, Di Trapani F, Sarhosis V (2015) A macro-modelling approach for the analysis of infilled frame structures considering the effects of openings and vertical loads. Struct Infrastruct Eng 12(5):551-566

Rodrigues H, Varum H, Costa A (2010) Simplified macro-model for infill masonry panels. J Earthq Eng 14(3):390-416

Polyakov SV (1960) On the interaction between masonry filler walls and enclosing frame when loading in the plane of the wall. Translation in earthquake engineering. Earthquake Engineering Research Institute, San Francisco, pp 36-42

M. Holmes, Steel frames with brickwork and concrete infilling, Proc. Inst. Civ. Eng. 19 (4) (1961) 473-478.

Liauw TC, Kwan KH (1984) Nonlinear behaviour of non integral infilled frames. Comput Struct 18:551-560

Thiruvengadam V (1985) On the natural frequencies of infilled frames. Earthq Eng Struct Dyn 13(3):401-419

El-Dakhakhni W, Elgaaly M, Hamid A (2003) Threestrut model for concrete masonry-infilled steel frames. J Struct Eng 129(2):177-185

Asteris PG, Antoniou ST, Sophianopoulos D, Chrysostomou CZ (2011) Mathematical macromodeling of infilled frames: state of the art. J Struct Eng (ASCE) 137(12):1508-1517

Calio` I, Panto` B (2014) A macro-element modelling approach of infilled frame structures. Comput Struct 143:91-107

Marques R, Lourenc,o PB (2014) Unreinforced and confined masonry buildings in seismic regions: validation of macro-element models and cost analysis. Eng Struct 64(52):67

Calio` I, Marletta M, Panto` B (2012) A new discrete element model for the evaluation of the seismic behaviour of unreinforced masonry buildings. Eng Struct 40:327-338

Marques R, Lourenc,o PB (2011) Possibilities and comparison of structural component models for the seismic assessment of modern

kamaran.kareem@uoh.edu.iq, hunar.hamaali@uoh.edu.iq, hiwahamidenineering@gmail.com, bedar.hassan@uoh.edu.iq, faraydon.hmahmod@yahoo.com

${ }^{1}$ Corresponding author: Department of Civil Engineering, University of Halabja, Kurdistan Region, Iraq 
unreinforced masonry buildings. Comput Struct 89:2079-2091

Macro D (2015) 3D computer program for the seismic assessment of masonry buildings. Gruppo Sismica s.r.l., Catania, Italy. Release 3.1

Carvalho EC, Coelho E (2001) Seismic assessment, strengthening and repair of structures. radECOEST2- ICONS report no. 2, European Commission-Training and Mobility of Researchers Programme.

Dolšek M, Fajfar P (2008) The effect of masonry infills on the seismic response of a four-storey reinforced concrete frame-a deterministic assessment. Eng Struct 30(7):1991-2001

Al-Chaar, G., Issa, M. and Sweeney, S., 2002. Behavior of masonry-infilled nonductile reinforced concrete frames. Journal of Structural Engineering, 128(8), pp.1055-1063.

Marques, R.F.P. and Lourenço, P.B., 2012. Pushover seismic analysis of quasi-static tested confined masonry buildings through simplified model. In 15th International Brick and Block Masonry Conference (pp. 1-10). Universidade Federal de Santa Catarina (UFSC).

Pinto AV, Verzeletti G, Molina FJ, Varum H, Carvalho EC, Coelho E (2001) Pseudo-dynamic tests on nonseismic resisting $\mathrm{RC}$ frames (infilled frame and infill strengthened). EU Special
Publication. ELSA, JRC-Ispra, EC, Lombardy

Varum H (2003) Seismic assessment, strengthening and repair of existing buildings. $\mathrm{PhD}$ thesis, Department of Civil Engineering, University of Aveiro, Portugal

Kareem, K.M. and Pantò, B., 2019. Simplified macro-modelling strategies for the seismic assessment of non-ductile infilled frames: a critical appraisal. Journal of Building Engineering, 22, pp.397-414.

Kareem, K.M. and Güneyisi, E.M., 2018. Effect of masonry infill wall configuration and modelling approach on the behaviour of RC frame structures. Arabian Journal for Science and Engineering, 44(5), pp.4309-4324.

Caddemi, S., Caliò, I., Cannizzaro, F. and Pantò, B., 2013. A new computational strategy for the seismic assessment of infilled frame structures. Proceedings of the 2013 CivilComp Proceedings, Sardinia, Italy, pp.3-6

Lee, J. and Fenves, G.L., 1998. Plastic-damage model for cyclic loading of concrete structures. Journal of engineering mechanics, 124(8), pp.892-900.

Lubliner, J., Oliver, J., Oller, S. and Oñate, E., 1989. A plastic-damage model for concrete. Int. J. Solids and Structures.

ABAQUS, online documentation. SIMULIA Inc.; 2011.

kamaran.kareem@uoh.edu.iq, hunar.hamaali@uoh.edu.iq, hiwahamidenineering@gmail.com, bedar.hassan@uoh.edu.iq, faraydon.hmahmod@yahoo.com 